Article

\title{
A Systemic and Systematic Approach to the Development of a Policy Mix for Material Resource Efficiency
}

\author{
Tomas Ekvall ${ }^{1, *}$, Martin Hirschnitz-Garbers ${ }^{2}$, Fabio Eboli ${ }^{3}$ and Aleksander Śniegocki 4 \\ 1 IVL Swedish Environmental Research Institute, Valhallavägen 81, SE-100 31 Stockholm, Sweden \\ 2 Ecologic Institut gemeinnuetzige GmbH, Pfalzburger Str. 43/44, D-10717 Berlin, Germany; \\ martin.hirschnitz-garbers@ecologic.eu \\ 3 Fondazione Eni Enrico Mattei (FEEM), Corso Magenta 63, 20123 Milano, Italy; fabio.eboli@feem.it \\ 4 Warszawski Instytut Studiów Ekonomicznych (WISE), Al. Jerozolimskie 99 lok. 18, 02-001 Warszawa, \\ Poland; aleksander.sniegocki@wise-europa.eu \\ * Correspondence: tomas.ekvall@ivl.se; Tel.: +46-101-788-6831
}

Academic Editors: Francesca Montevecchi, Martin Hirschnitz-Garbers, Tomas Ekvall, Martha Bicket and Patrick ten Brink

Received: 7 February 2016; Accepted: 7 April 2016; Published: 15 April 2016

\begin{abstract}
Increasing material use efficiency is important to mitigate future supply risks and minimize environmental impacts associated with the production of the materials. The policy mix presented in this paper aims to contribute to reducing the use of virgin metals in the EU by $80 \%$ by 2050 without significant shifting of burdens to other material resources, environmental impacts, or parts of the world. We used a heuristic framework and a systems perspective for designing the policy mix that combines primary instruments designed to increase material efficiency, recycling and substitution of materials (a materials tax, the extended producer responsibility, technical regulations, and environmental taxes) and supportive instruments aimed to reduce barriers to implementing the primary instruments and to contribute towards the policy objectives (e.g., research and development support, and advanced recycling centers). Furthermore, instruments were designed so as to increase political feasibility: e.g., taxes were gradually increased as part of a green fiscal reform, and border-tax adjustments were introduced to reduce impacts on competitiveness. However, even in such a policy mix design ongoing ex-ante assessments indicate that the policy mix will be politically difficult to implement-and also fall short of achieving the $80 \%$ reduction target. Nonetheless, we suggest combining primary and supportive instruments into coherent and dynamic policy mixes as a promising step towards system reconfigurations for sustainability.
\end{abstract}

Keywords: policy mix; policy development; resource efficiency; material efficiency; recycling; European Union; Sensitivity Model

\section{Introduction}

Global consumption of material resources has seen marked increases in the last century, in particular since the 1950s [1-4]. The use of resources and, in particular, the production of bulk materials (steel, aluminum, cement, polymers, and paper) is responsible for a significant share of the energy demand and greenhouse gas (GHG) emissions of human society $[5,6]$. Transforming these materials into consumption goods, infrastructure, and housing also generates significant environmental impacts. This contributes to the continuing degradation of a large share of ecosystems [7], to the $50 \mathrm{Gt}$ $\mathrm{CO}_{2}$-equivalents emitted annually [8], and to the global ecological footprint of human activities, which in the year 2005 amounted to more than 1.4 planet Earths [9]. 
Global megatrends risk exacerbating the situation in the future and further challenge the likelihood and feasibility of transitioning to more sustainable resource use pathways. Rising global population and affluence levels, ever more widespread adoption of westernized lifestyles, and production and consumption patterns will contribute to future increases in resource consumption, which is expected to reach approximately 140 billion tons of minerals, ores, fossil energy carriers, and biomass by 2050 [10], more than doubling from the 68 billion tons reported for 2009 [1]. Such resource use and associated environmental impacts contribute to (further) transgressing existing planetary boundaries [11]. Human activities are expected to require two planet Earths around 2030 [12] and fossil-fuel-dominated energy use will increase by almost $80 \%$ by 2050 [13].

We are not likely to run out of material resources in the foreseeable future, but the production rate of renewable materials is limited and the economic cost of producing non-renewable materials is likely to increase with time, particularly if material use continues to increase [14]. Increasing the efficiency in the use of material resources is important to generate as much economic value and/or well-being and serve as many functions as possible with a given resource base. Furthermore, increasing resource use efficiency can counteract risks related to future supply of certain materials, for example rare earth metals [14], because the mineral reserves and/or mines are located at very few places in the world.

Hence, increasing efficiency in the use of material resources is important to steward our resource base and enable present and future generations to benefit from using resources sustainably, thus increasing the resilience of social-ecological systems and achieving a more sustainable economy in the long term. The use of material resources can be more efficient through increased recycling, but also through increased material efficiency. The latter can include material-efficient production processes, material-lean products and systems, products with a long service life due to high quality and reparability, changes in consumption patterns from products to services, from owning to sharing, etc. [15].

Policy-making for resource efficiency is a complex and large-scale challenge. A single material is typically used in many different applications and sectors. Economic interlocking of streams of resources, semi-finished and finished goods makes resource policy a policy field involving a multitude of interdependent actors in value chains that cross national boundaries and on markets that are often global. Taking into account the specific conditions of each application and each actor is hardly possible, and yet, failing to do so increases the risk that policy interventions shift the use of resources to other applications or regions of the world, rather than increasing resource efficiency. Furthermore, efficiency gains obtained from improving resource use efficiency may trigger greater consumption of the same good/service or of other goods and services, eventually backfiring and causing rebound effects [16].

These complexities, the many functions that material resources serve, and the multitude of involved actors in multi-level-systems, call for a more systemic approach to resource policy-making. Such an approach would need to allow policy makers to account for the most important aspects and causal relations between relevant trends and drivers and their effects when designing policies. Furthermore, such an approach requires a very broad systems perspective in order to capture as much as possible the system's complexities.

There is much literature analyzing policy instruments for recycling and material efficiency, and their potential effects. Such studies focus, for example, on extended producer responsibility [17], raw materials taxes [18], landfill taxes [19], and incineration taxes [20]. Söderholm and Tilton [21] argue that policy for material efficiency should focus on addressing the environmental impacts and the information failures, rather than specific technologies, since material efficiency is important mainly because of the environmental impacts associated with materials production, and not because of looming material scarcity. Finnveden et al. [22] assessed 13 different instruments for waste prevention and recycling, and found the following to be promising: information, compulsory recycling of recyclable materials, a weight-based waste-collection fee, labelling of products with hazardous content, limitations to direct advertising to mailboxes, and reduced value-added tax (VAT) on services other than transports. However, their model results indicated a limited impact on the total waste quantities: reducing the 
VAT on services from $12 \%$ or $25 \%$ to $6 \%$ made the total waste quantity fall by $1.5 \%$. Other instruments appeared to be less effective. A tax of 1.2 US\$/ton extracted material, for example, reduced the waste quantity by less than $0.1 \%$ in the model.

A large share of existing studies looked at individual instruments, while much fewer address combinations of policy instruments. Finnveden et al. [22] discussed weight-based waste-collection fee in combination with information and improved collection systems. Söderholm [18] assessed the combination of raw materials extraction taxes and landfill taxes. They argue that these combinations of instruments are more effective than a separate weight-based fee or a separate raw materials tax.

Combinations of policy instruments have also been applied in various areas of environmental policy [23], inter alia: for a more sustainable management of Icelandic fisheries, by setting total allowable catch rates, introducing individual tradable quotas and adding a fisheries resource rent tax $[24,25]$; for reducing plastic waste in the environment in Ireland through introducing a tax on plastic bags accompanied by voluntary initiatives and awareness-raising campaigns [26]; for reducing fertilizer use in Denmark through national action plans comprising fertilizer taxation, monitoring, and enforcement mechanisms and farmer extension services $[27,28]$. However, in several examples, the policy mixes seem to have been designed in the sense of adding new policy instruments when necessary without considering potential interactions and long-term consistency between instruments (so-called policy-layering [26,27]).

Green tax reforms are a combination of instruments that has been analyzed in several studies. Green tax reforms combine increased environmental taxes with reduced taxes on labor and/or investments. Green fiscal reforms expand on the tax reform to also include a shift from environmentally-harmful to environmentally-beneficial subsidies. Such a combination of instruments can not only reduce environmental impacts but also stimulate economic growth and employment [29], depending on details in the reform and its context [30]. If a green tax reform is implemented in a single step, the short-term costs can be high [31].

Policy-making for efficient use of material resources needs to apply an even broader approach, because of the great complexity involved. In this context, the concept of policy mixing seems promising. A policy mix combines several policy instruments aimed at achieving one or several interlinked policy objectives by (a) tackling the most important drivers underlying the need for policy support; and (b) trying to maximize positive relations between the instruments.

In political science, looking at policy instrument mixes has emerged as a more nuanced model for analyzing public policy in the 1990s. For instance, Gunningham and colleagues [32,33] focused on optimal policy intervention by integrating selective regulation with market-based approaches to design sophisticated instrument mixes. Further research showed that both the design and the implementation of policy mixes are very much context dependent and, hence, are complicated by information deficiencies, existing actor constellations, and strategic considerations, which enter decision-making processes in real-world situations and increase the risk of mismatch between policy instruments and outcomes [34,35]. In order to successfully respond to and be adapted to the specific context [36], the development of policy mixes needs to consider:

- The full range of policy instruments;

- Costs of policies (implementation costs, transaction costs, compliance costs);

- Potentially negative side-effects of policy on target groups (e.g., issues of competitiveness of policy addressees from industry, or regressive effects on lower-income households);

- Options to combine instruments to mitigate such side-effects; and

- Political processes during design and implementation.

The project "DYNAmic policy MIXes for absolute decoupling of environmental impacts of EU resource use from economic growth" (DYNAMIX, FP7 project [37]) has tested a systematic approach in developing a policy mix for reducing consumption of metals and other material resources in the EU by 
2050. The procedure for developing the policy mix has been reflected upon and revised as part of the DYNAMIX project. This paper describes this approach and uses the policy mix for material-resource efficiency as an example to illustrate the procedure. This makes the contribution of the paper two-fold. In the area of materials policy, we aim to present a promising, coherent and consistent policy mix for materials resource efficiency. In the more general policy area, we aim to show how the policy mix concept can be used as a guiding heuristic to design coherent and consistent policies, and to avoid policy layering.

This paper outlines the multi-step development process and details the policy mix designed. For this purpose, we will first describe the development process and the heuristic framework used (Section 2) and then detail the policy mix following the different steps of the heuristic framework (Section 3). Then we will discuss (Section 4) both the policy mix and the conceptual approach used.

\section{Materials and Methods}

\subsection{Heuristic Framework for Designing Policy Mixes}

The DYNAMIX project aims to identify and assess dynamic and robust policy mixes to shift the EU onto a pathway to absolute decoupling of long-term economic growth from resource use and environmental impacts and to reduce resource use to a sustainable level.

Three DYNAMIX policy mixes were developed (one of which is the metals and materials policy mix presented here) through a systematic systems approach elaborated based on the heuristic framework adapted from Givoni et al. [38]. This encompasses the following stages (see Figure 1 below):

(1) Defining longer-term objectives and setting short- to medium-term, more concrete, targets for the respective policy areas;

(2) Elaborating a theoretical causal model for problem solving in the policy areas (What is the problem situation? What are contributing drivers? What does impede changes?);

(3) Selecting, based on heuristics and expert guessing, promising instruments from known potentially relevant policy instruments contributing to problem solving to form an initial policy mix;

(4) Undertaking ex-ante assessments (literature based qualitative assessments, participatory scenario building, and quantitative computer model simulations) of the initial policy mix as to its potential effectiveness and impacts. This usually entails comprehensive scientific analyzes, which then enable substantiated decision-making as to whether or not to include the instrument analyzed into the mix;

(5) Adding, if the initial mix was found sub-optimal against the set objectives and targets, further instruments to the mix or revising existing instruments and re-running the assessment (repetition of Stages (4) and (5)) to finalize the policy mix; and

(6) Preparing the final policy mix for implementation, enforcement, and monitoring.

The final stage of the framework was not undertaken as the DYNAMIX project aims to give recommendations to European and national policy-makers, but not to prepare a mix for implementation or enforcement.

A policy mix goes beyond combining loosely or rather unconnected policy instruments. In fact, in a policy mix long-term qualitative objectives and short- to mid-term quantitative targets are linked to an instrument set applied in a time-dynamic sequential process approach to achieve the objectives and targets. Therefore, compiling a policy mix requires:

- A forward-looking roadmap, i.e., relating different policy instruments to each other in a time sequence that helps optimizing synergetic effects and minimizing unintended negative side-effects; and

- Consideration of political processes in multi-actor networks and polycentric governance systems in order to be able to monitor processes and adapt the mix in feedback loops over time. 


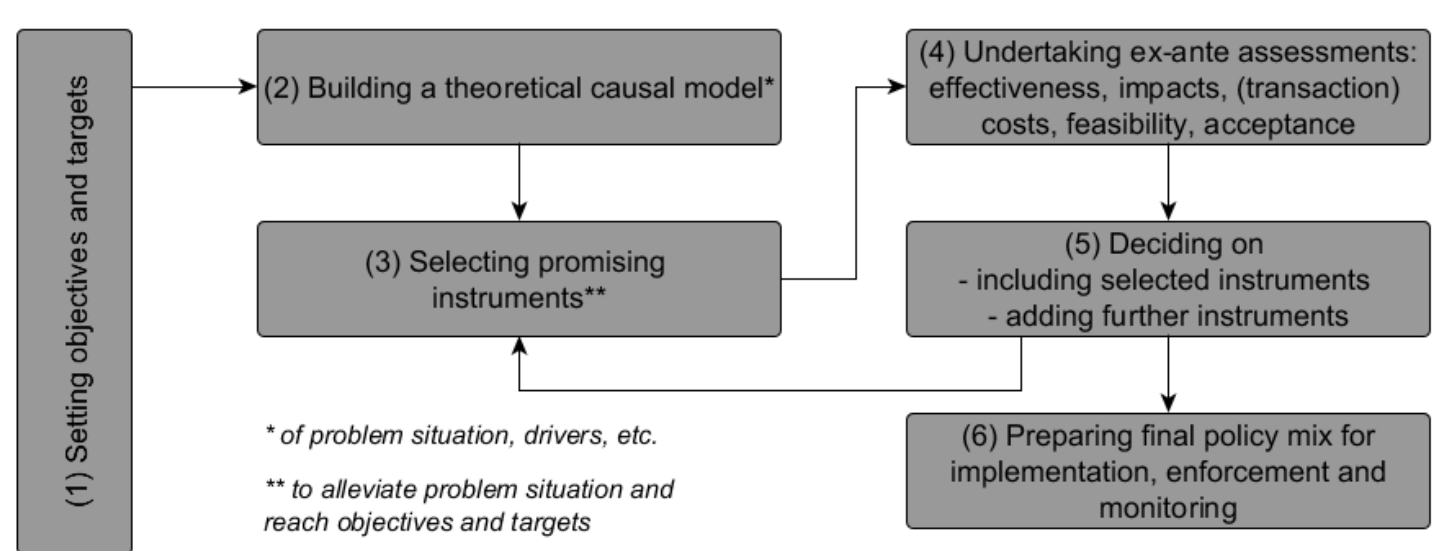

Figure 1. Heuristic framework for policy mixing. Source: adapted from [38].

Thus, the concept of policy mixes appears to clash with political practices and experience, where policy formulation often entails so-called policy layering, i.e., stacking new instruments or objectives on top of existing ones without any overarching design $[28,36]$. Resulting from political needs, such as existing alliances, election-based tactics, or lacking time or knowledge, policy layering increases the risk of unplanned mixes with contradicting objectives and measures and, hence, of trade-offs in effectiveness.

Designing, implementing, and evaluating policy mixes is much more difficult than loosely bundled individual instruments. Political realities, as well as the dynamics and path dependencies of legislative periods, run counter to a strategic and more long-term implementation procedure of policy mixes. Therefore, compiling a policy mix needs to consider political process in multi-actor polycentric governance systems to identify and exploit opportunities for long-term, adaptive policy formulation.

In this context, designing a policy mix needs to ensure a good fit between instruments and targets within a single level of policy (horizontal mixing), as well as with institutional framework conditions (i.e., various policy fields and governments active in these fields $=$ vertical mixing) $[28,34]$. This encompasses the need to consider both consistency and coherence of the instruments sequentially linked in a policy mix. While consistency, in a more narrow sense, denotes the absence of conflicts and contradictions, coherence refers to ensuring synergetic effects and positive interactions between instruments (denoted as strong consistency by Rogge and Reichhard [39]) as well as between different policy and administrative levels [36,39].

Consistency and coherence can be fostered by combining primary with supportive instruments. Primary instruments mainly serve to achieve the/a set objective and should be as little controversial as possible; supportive instruments serve to minimize or mitigate unintended negative side-effects of primary measures and, hence, to increase their acceptability and feasibility [38,39].

\subsection{The Process to Designing the Metals and Materials Policy Mix}

A target for reduced use of virgin metals in the EU was defined at the outset of the DYNAMIX project [40]. The target was quantified in terms of raw materials consumption (RMC), which is essentially the quantity of ore extracted to produce the metals.

A handful of representatives from different project partners, countries, and scientific disciplines was given the task to develop a policy mix aiming at supporting, if not achieving, this target. This team added further objectives specifically to this policy mix, widening its scope so as to avoid that the policy mix mainly causes burden-shifting to other regions or materials.

We used European statistics to identify the metals that dominate the total use of virgin metals. A literature review and background knowledge were used for identifying the drivers of the use of these key metals and the barriers to more efficient use of both the metals and other materials. 
Part of the background knowledge was synthesized through the use of the Sensitivity Model. This is a computer supported management and planning tool developed to assess and represent complex systems by (a) capturing and visualizing relevant areas and parts influencing a system; (b) making interrelations and interdependencies transparent; (c) identifying the relevant levers and critical elements to steer a system into the desired direction; and (d) allowing for scenario simulation [41]. The team used the first three elements for developing the policy mix. Scenario simulation could, in principle, be used for assessing a policy mix; however, the simulation in the Sensitivity Model is highly dependent on a few critical and typically rough estimates and we have selected more advanced modeling tools available in the project consortium (macro-economic models, life cycle assessment, etc.) over the use of the sensitivity model for the assessment of the policy mix. Hence, we applied only the following steps of the Sensitivity Model procedure:

(1) Identifying 20 to 40 of the most important variables (GDP, resource use, environmental pollution, etc.) in the policy field;

(2) Finding consensus on qualitative estimates of the interlinkages and causal relations between these variables;

(3) Analyzing the systemic role of each variable to identify the most sensitive (i.e., strongly affected by policy instruments or other variables), active (i.e., affect other variables strongly), or critical (i.e., strongly affected by and strongly affect other variables); and

(4) Creating a so-called Effect System to illustrate the interdependencies among parameters.

Based on this procedure, the team combined a preliminary set of policy instruments promising to tackle the identified drivers and barriers into a dynamic policy mix [42]. This policy mix was presented to the rest of the DYNAMIX researchers during project meetings and to a wider audience during stakeholder workshops (DYNAMIX policy platforms). It was then tested through ex-ante assessments for effectiveness, efficiency, and sustainability. The ex-ante assessment is, in part, done through environmental [43] and economic [44] quantitative modelling. Such models are powerful tools for assessing economic and environmental impacts in the EU and globally; however, many aspects are difficult to quantify or model with these tools. DYNAMIX, thus, also systematically integrates qualitative assessments of environmental [45], economic [46], social [47], and legal [48] aspects of the policy mix, as well as its public acceptability [49], to fully assess the real-world performance of the proposed policy mixes. We used the results from the ex-ante assessments to revise the policy-mix. Hence, the policy mix presented in this papers is based both on the analysis of the existing situation, the process of developing the policy mixes, and the results and insights from the assessments of the initial policy mixes.

\section{Results}

\subsection{Objectives and Targets for the Policy Mix}

The DYNAMIX project has the overall objective of absolute decoupling and sustainability. The broad concept of sustainability has been operationalized for environmental sustainability by setting five key targets for the year 2050 [40]:

- Consumption of virgin metals: to be reduced by $80 \%$, measured as RMC, compared to 2010 levels in the EU. This target represents the scarcity of metals and environmental impacts caused by extraction, refinement, processing, and disposal of metals;

- GHG emissions: to be limited to two tons of $\mathrm{CO}_{2}$ equivalent per capita per year. This is to be measured as a footprint to reflect both emissions generated within the EU and those embedded in imported products. This target represents climate change impacts of greenhouse gas emissions through energy use, as well as agricultural and industrial processes; 
- Consumption of arable land: to reach zero net demand of non-EU arable land. This target represents, as a rough approximation, the impacts of biomass production on soil quality, water quality, and biodiversity;

- Nutrients input: reducing nitrogen and phosphorus surpluses in the EU to levels that can be achieved by the best available techniques. This target represents the impacts of agricultural production on marine and freshwater quality, as well as soil quality; and

- Freshwater use: no region should experience water stress.

The target on metals is based on previous research [10,50] and was set to help reduce resource consumption in industrialized countries by $60 \%-80 \%$ to reach a sustainable level, at least for abiotic resources like metal ores, non-metallic minerals, and fossil energy carriers. The use of fossil energy carriers and non-metallic minerals (e.g., phosphorous) are covered by other targets set out in the DYNAMIX project, because they are strongly linked to GHG emissions and the use of nutrients. For this reason, the target for reduced use of abiotic resources focuses on metals. This was the primary target of our policy mix. Two other policy mixes were developed within the DYNAMIX project to respond to the other four targets: a policy mix on land use and an overarching policy mix.

The use of virgin metals can be reduced through a gradual increase in material use efficiency, in metals recycling, and through substitution by other materials. An increase in material efficiency here means a reduction in the quantity of materials required to provide a specific function or produce a monetary unit of economic output.

Although the geographical scope of the policy is the EU, the policy needs to also account for impacts beyond its boundaries. A policy that simply shifts material resource use or environmental impacts from the EU to other parts of the world does not address global environmental justice nor realities of complex international value chains. To reach a sustainable future, the global recycling rate is more relevant than the recycling that takes place within the EU. The share of recycled material used in the EU has only limited relevance on a global scale and to stay within planetary boundaries. Metals are traded globally and recycled metals are a good substitute for virgin metals. If EU policy increases the use of recycled metals in the EU, this will likely shift the use of virgin metals to other countries rather than increase the global recycling rate. To increase the global recycling rate, it seems more efficient to increase the supply of recyclable material from the EU through improvements in, for example, the sorting and collection of waste.

Metals compete with many other materials in important applications: with concrete and wood in construction, with paper and glass in packaging, with polymers in packaging and in components in machinery, and with textiles in furniture. However, shifting to the use of other materials sometimes is detrimental for the environment, the economy, or other societal goals. A steel bridge can have less climate impacts than a conventional bridge in reinforced concrete [51]. The use of steel frames for casting concrete in construction can also bring environmental advantages, compared to traditional wood frames [52]. To avoid burden-shifting to other material resources, the scope of the policy needs to be expanded to include not just metals but also the competing materials. Therefore, the objectives of the policy mix are to:

- Increase material efficiency for metals and all competing materials;

- Increase the global recycling rate of these materials; and

- Substitute metals with other materials, where this is beneficial for the environment and well-being.

\subsection{A Causal Theory for Problem Solving}

\subsubsection{Drivers for Metal Use}

Consumption of virgin metals in the EU is dominated by iron, copper, and gold (see Figure 2). Reducing virgin metals use by $80 \%$ requires measures to significantly reduce the use of at least these three metals. 
Metals are used in all sectors of the economy; hence, metal use has a diversity of drivers. Key drivers causing unsustainable resource use, in general, were identified at the early stages of the DYNAMIX project [53]: the identified materials-related drivers included, e.g., proliferation of consumption-based lifestyles linked to rising income and emerging social norms of material aspirations, or resource prices, which are both increasingly volatile and (still) mostly ignorant of the true external costs of the resources' use. We found the drivers to affect each other in a complex web of causal relationships much rather than in simple causal chains. The Sensitivity Model (see Section 2) allows us to analyze a simplified version of this web, where we selected only 29 variables out of the almost infinite number of variables in the real economy. When we illustrate the web, we can also select to present only the strongest causal relationships between these variables: the arrows in the Effect System (Figure 3). Note that besides these strong relationships, there are many more, weaker relationships between the variables in the Sensitivity Model.

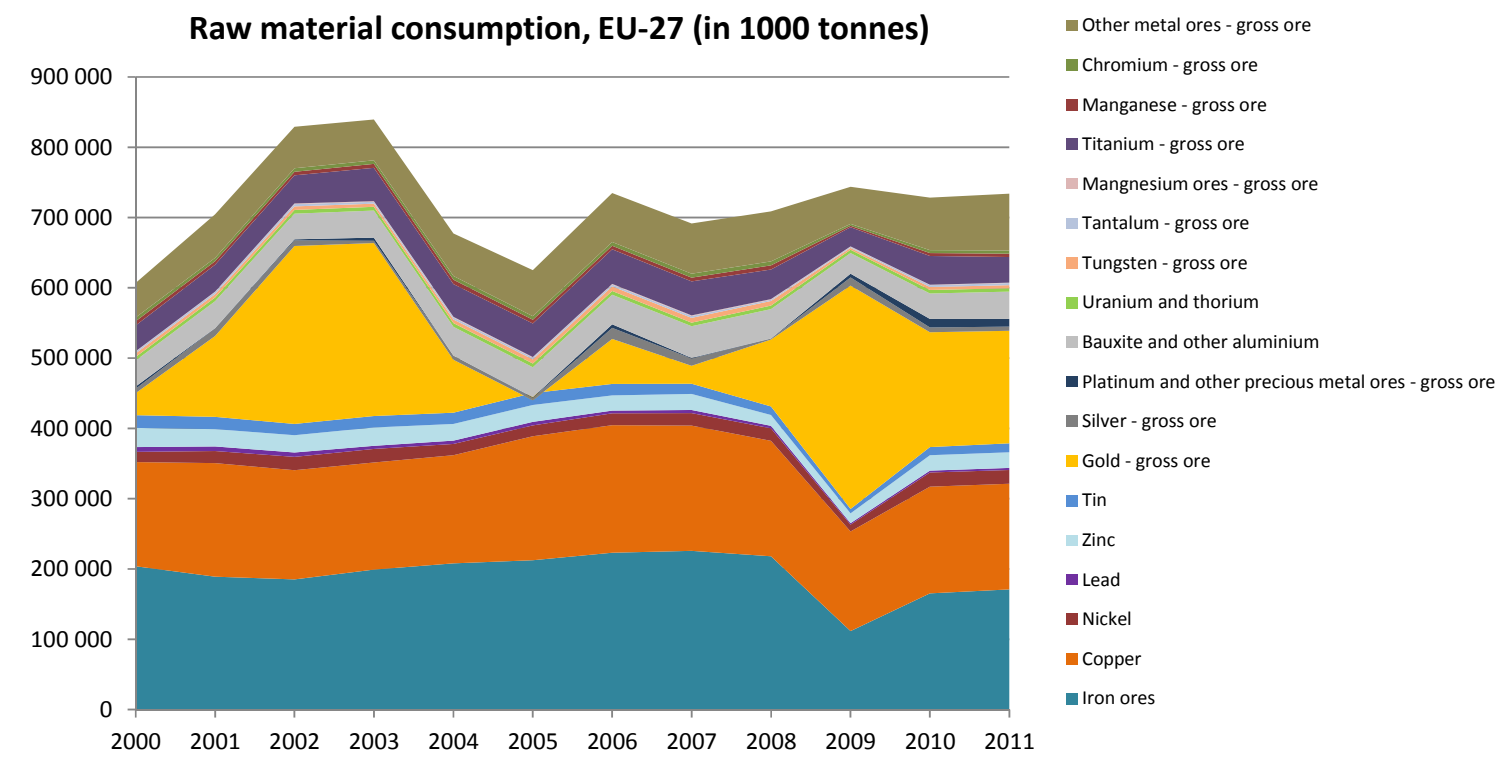

Figure 2. Metal use in the EU-27 ([42] based on [54]).

Iron is mainly used for the production of steel. Steel is, to a large extent, used for the construction and maintenance of buildings and infrastructure (56\% globally, $35 \%$ in the EU), but also in machines, vehicles, and many other products $[55,56]$. This means that expansion and replacement of infrastructure, housing, and commercial buildings are important drivers for steel use (Variable 1 in Figure 3). The growth of transport equipment, machinery, and appliances is also a significant driver. All of these are closely linked to economic growth (Variable 22). However, there is evidence that per capita requirements for steel stocks saturate around 10 tons per person [57].

Our application of the Sensitivity Model did not result in any strong causes to the use of copper (Variable 2 in Figure 3) among the other variables in the model. However, the major current applications of copper are in electrical wires (about 60\%), construction (e.g., roofing and plumbing) (about 25\%), and industrial machinery (about 10\%) [58]. Wires are used to transport electric energy over long distances and within most electric products. Hence, the expansion of electricity systems (including, for example, the requirement for connecting new renewables capacity to grids) and production of electrical products are important drivers for copper use. Similar to steel, the demand for new buildings, infrastructure, transport equipment, machinery, and appliances (very much linked with economic growth) also drives the demand for copper. Copper consumption per capita seems to be linked to GDP per capita, at least until about $12-14 \mathrm{~kg}$ per capita.

The pattern of gold use (Variable 3 in Figure 3) is quite different from iron and copper. Most of it is used because of its symbolic value to produce jewelry (about 50\%) and for investments such 
as coins and bars (about 40\%) [59]. Only smaller quantities of gold (10\%) are used for its technical properties in electronic products, chemical industry, embroidery, etc. The use of gold in jewelry, on the other hand, might be driven to a large extent by the desire to signal status, or by the urge to show love and affection. This is relatively independent from economic growth, although it might be affected by changes in the income inequalities and the distribution of wealth within a country. Coins and bars are used as safe investments during economic disruption. Such gold use is driven by the need for economic safety rather than by economic growth. Gold stocks in countries are constantly traded and not "consumed" as such in an economy. As a result the net gold import to the EU can fluctuate between large and below zero from one year to another (Figure 2).

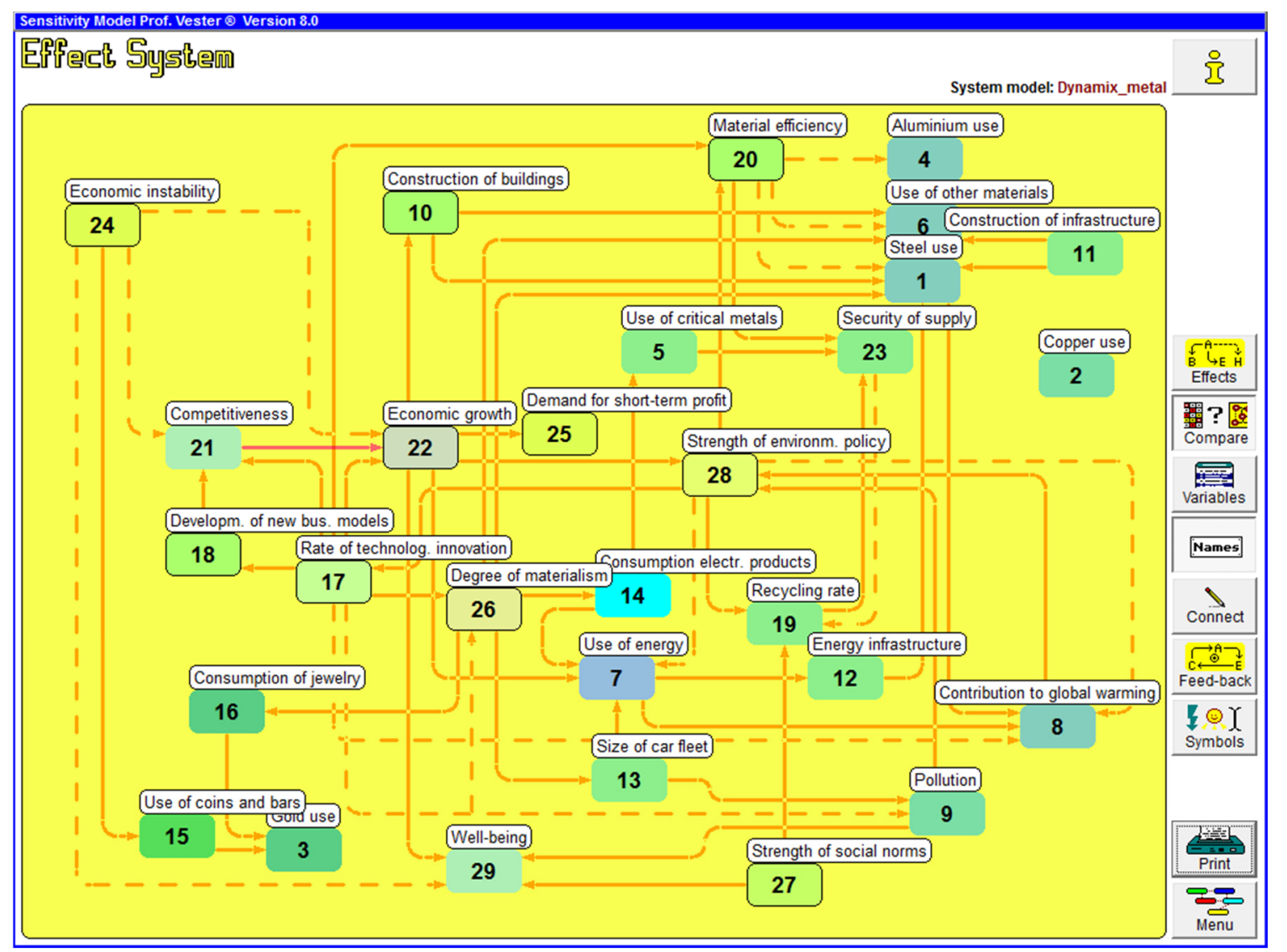

Figure 3. The Effect System from the Sensitivity Model illustrates a few of the most important causal relationships between the variables in the system affected by the metals and materials policy mix ([42]). The 29 variables selected are given a number as well as a short name in the figure. Solid arrows illustrate a strong positive causality, where an increase in one variable causes an increase in the other. Dotted arrows illustrate a strong negative causality, where an increase in one variable causes a reduction in the other.

The use of virgin metals is also strongly affected by the recycling rate. If kept pure, metals can, in theory, be indefinitely recycled. It is estimated that some $80 \%$ of post-consumer steel is recycled [60]. The recycling rates are the highest for heavy structures, motor vehicles, and machinery $(85 \%-95 \%)$ and lower for smaller appliances and packaging, etc. (around 50\%). At present about 38\% of high-alloyed steel and $41 \%$ of low-alloyed steel used in the economy is from recycled iron and steel [61].

Most of the copper in used products is recovered for recycling because of its high value. However, copper that ends up in steel scrap is lost and unavailable for recycling. Estimates of the total recycling of copper in global post-consumer scrap range from $43 \%$ to $53 \%$ [61]. At present about $27 \%$ of copper demand is satisfied by secondary raw materials. 
The gold in coins, bars, and jewelry is easy to recycle. Gold on printed circuit boards from electronic products can also be recycled, but requires special sorting and dismantling. The recycling rate of gold in global post-consumer scrap has been estimated to be $96 \%$, if re-melting of jewelry and coins is accounted for. If gold in coins, bars, and jewelry are excluded, the recycling rate might be as low as $15 \%-20 \%$ [61].

\subsubsection{Barriers to a More Efficient Use of Materials}

A barrier to reducing the overall consumption of materials is the predominant business model of prevailing industrial systems. Companies base their revenue on the sale of products. The revenues and profits of the companies typically increase with the number of products sold. This drives an increase in the use of metals and other materials [42]. Barriers to a shift to service- or function-based business models can be found at various levels: among producers (e.g., the perception of the core business of the company and the risks associated with a change in business model), in the markets (e.g., lacking information on the total cost of ownership), and among consumers (e.g., the perception that ownership is necessary to ensure control and availability).

Resource efficiency can be increased through increased reuse of products and components and through increased recycling of materials. A fundamental barrier to such a circular economy is that the quantity of used components and scrap material in the long run cannot be greater than the quantity of products that are taken out of use. Other barriers to include cover the labor costs related to, for example, source separation at work places; the reluctance among households to spend much time and effort on source separation of waste; and a lack of reverse logistics infrastructure. This contributes to making the supply of recycled material insensitive to changes in demand [62].

Recycled metals are traded in a global market, where recycled and virgin materials are good substitutes in many applications. This is apparent from the international prices for steel, aluminum, and copper, where the correlation is strong between the variation over time in prices for virgin and recycled material [63]. Since the quantity in the recycled market is limited on this global market, a policy that focuses on increasing the use of recycled metals in the EU risks resulting in reduced use of recycled metals elsewhere. As a result, the use of virgin material will merely be shifted to other parts of the world. Policies that increase the availability of recyclable or recycled metals are more effective contributions to increasing global recycling rates. Similar arguments also hold for paper.

For other materials, such as polymers and textiles, recycled material is a less adequate substitute for virgin materials. Here, a lack of knowledge and trust in the supply of recycled material, and a mismatch between the actual supply and demand for recycled material can be barriers to the use of recycled material and, hence, to increased recycling.

Resource efficiency can also be increased through making products more material-lean and processes more material-efficient. Barriers to more material-efficient product designs include economic arguments (it is often cheaper to use larger amount of materials than to carefully design material-lean products), technical requirements (companies often prefer to use extra material to ensure a robust and reliable product rather than carry the risk of product failure), and customer perceptions (a light-weight product can be perceived to have lower quality) [55].

A key component in many of the barriers above is the fact that the highly automated large-scale production of bulk materials has made them relatively cheap compared to the labor costs involved in services, reuse cycles, product design, etc.

However, investments in more resource-efficient technologies are not necessarily made even when they are profitable. This can be due to a lack of capital or because corporate management decisions focus less on the production processes than on the products that are the core business of the company, but also on several other barriers that are specific to the company [64].

A reduction in the use of virgin metals by $80 \%$ is a drastic change in the material flows. A policy mix that achieves this target will affect producers of metals and other materials around the world. Manufacturing companies with the traditional business model might lose out, while service-based 
companies might gain. The implementation of such a policy mix is likely to encounter resistance from incumbent industries that risk losing profitability, from regions and countries that depend on such industries, and from unions with workers that risk losing their jobs. The policy is likely to create new jobs, but perhaps not at the same location and probably not with the same skill requirements. All this creates barriers to implementation of the policy mix.

\subsection{Promising Policy Instruments}

The metals policy mix includes four primary instruments:

(1) A tax on all metals and competing materials used in the EU to increase material efficiency. The tax is introduced at a very low level in 2020 and gradually increased to a level that is high enough to make the construction and manufacturing industry significantly more material-efficient. The materials tax is presented and discussed in Section 3.3.1.

(2) Extended producer responsibility schemes are expanded in 2020 to new product groups and countries, with the primary aim to increase recycling, but also contributing to material efficiency (Section 3.3.2).

(3) Technical requirements that specify the type and quantity of materials that can be used in specific products are introduced in 2030, with the aim to substitute metals where appropriate, and to increase material efficiency (Section 3.3.3).

(4) External costs are internalized through gradually expanded and increased environmental taxes from the year 2020, with the aim to improve recycling material efficiency and substitution when these are beneficial for the environment (Section 3.3.4).

The economic and legal primary instruments are embedded, supported and, in some cases, preceded by a larger set of softer and/or less controversial supportive instruments (see Figure 4): border taxes are adjusted to reduce the impacts on the competitiveness of EU industry (Section 3.3.5); labor taxes are reduced to stimulate economic growth and employments (Section 3.3.6); increased funding for research and development on recycling and material efficiency to facilitate changes in technology (Section 3.3.7); metals-related environmentally-harmful subsidies are removed with the aim to make the policy mix easier to communicate and also to increase material efficiency (Section 3.3.8); sharing systems and advanced recycling centers are developed to make resource efficiency easier for the public (Sections 3.3.9 and 3.3.10); education programs are established to retrain the workforce to better fit a restructured economy (Section 3.3.11); and measures are taken to facilitate communication among and between policy-makers, business, researchers, and the public (Sections 3.3.12-3.3.14). These supportive instruments aim to reduce the barriers to implementing the policy mix but also contribute to reducing barriers to direct increases in resource efficiency.

A green fiscal reform is an important part of this policy mix. It includes the materials tax, the environmental taxes, the removal of harmful subsidies, and the reduced labor taxes. The tax revenues and reduced spending are used for reducing labor taxes to the extent that they are not used for funding the rest of the policy mix. 


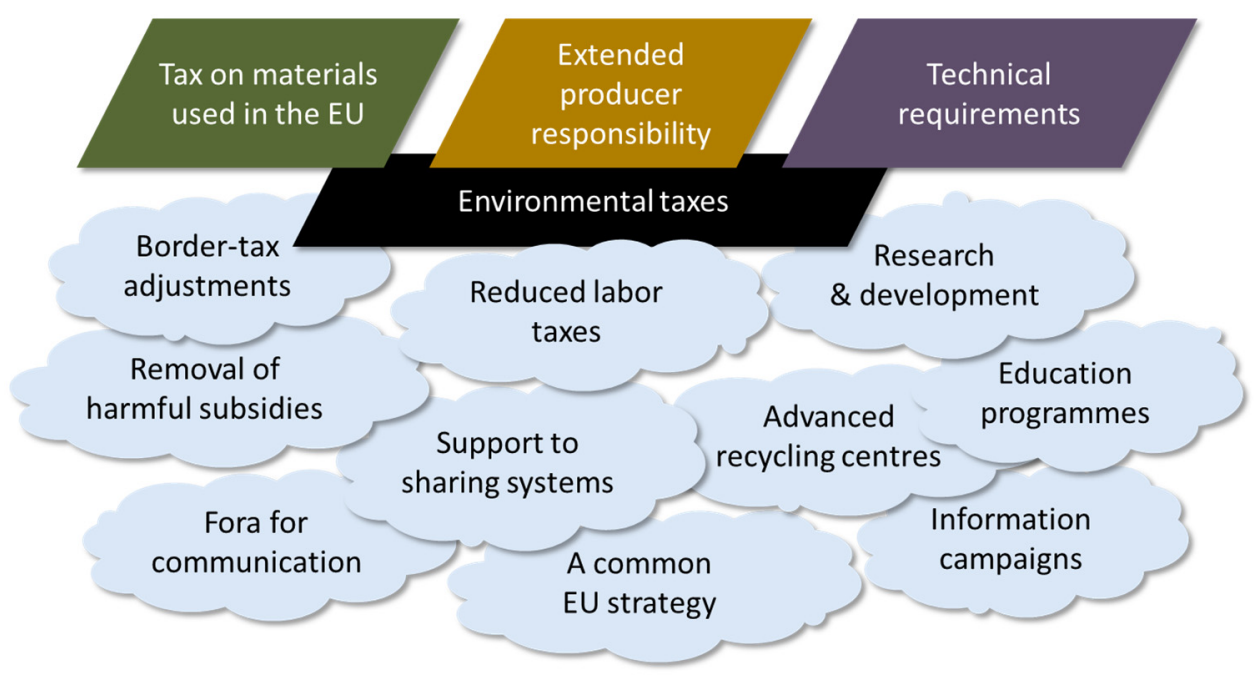

Figure 4. Illustration of the policy mix for metals and other materials. It includes a combination of primary instruments (rhomboid) and supportive instruments (cloud-shaped).

\subsubsection{Materials Tax}

The materials tax aims specifically at increasing material efficiency, primarily in the manufacturing and construction industry. It is a tax on all materials that are used in the EU: steel, concrete, paper, polymers, glass, textiles, etc. The materials tax is to be levied on all types of materials in order to avoid burden shifting from metals to other materials. It is levied even on renewable materials; also, renewable material resources need to be used efficiently, because the production rate of renewable material is limited ( $c f$. Section 1$)$.

The materials tax is levied regardless of whether the material is produced from virgin, natural resources, or from recycled raw material. The tax is also applied on recycled material since it aims specifically to increase material efficiency. Furthermore, if the tax is also applied on imported material, as we suggest (see Section 3.3.5), it is much more difficult to implement on virgin materials only. This is because virgin and recycled materials are often mixed and sometimes impossible to distinguish from each other.

- It can be argued that implementing a tax on virgin materials would only stimulate recycling in addition to material efficiency, because it would make recycled materials relatively cheaper to use in the EU. However, as discussed in Section 3.2.2, a policy that focus on increasing the use of recycled metals in the EU is not likely to be very effective in increasing the global recycling rates, at least not for metals and paper.

The demand for materials is relatively inelastic. This means that a materials tax needs to be high to significantly affect the material efficiency. Ekvall et al. [42] suggest that the tax is introduced at a very low level in the year 2020, then gradually increased to $30 \%$ of the net value of the material in 2030 and to $200 \%$ of the net value of the material in 2050 .

The material tax can take either of two different forms. It could be a value-based tax, which is levied on the traded quantities of finished materials to and within the EU. Alternatively, it could be a weight-based tax levied on the extraction of raw materials from nature and the traded quantities of recovered recyclables to and within the EU. A value-based tax is simpler to decide on and revise because the tax rate is negotiated and decided for all materials at the same time. A value-based tax also automatically reflects the scarcity of different materials to the extent that the scarcity affects the net price of the material. The drawback is that it is not just a tax on the (virgin and recyclable) material resources but also a tax on the labor and capital costs of the materials industry. 
The weight-based tax has the advantage that it is a tax on virgin and recyclable raw materials only. In addition, it reduces the volatility of the material costs in the manufacturing and construction industry. This makes it easier for the industry to invest in and plan for material efficient processes and procedures. However, the level of a weight-based tax needs to be separately decided for each raw material and each flow of recyclables. When applied on recyclables it might also create barriers to the collection of recyclable material in the EU.

\subsubsection{Extended Producer Responsibility}

The extended producer responsibility (EPR) is the instrument in the mix that specifically aims at increasing materials recycling. A supply of recyclable material is a prerequisite for recycling of all materials. For metals and paper, where a global market for recycled materials is well established and where recycled and virgin materials compete in many applications, an increase in the supply of recyclable material is the most effective way to increase global recycling.

The EPR means that producers in a broad sense are given the responsibility for securing a specified level of collection and recycling of their own products and packaging. A system of EPR is already implemented in the legislation of several Member States. Our policy mix includes an expansion of EPR to additional product groups (and to materials, rather than product groups) in all Member States.

The EPR scheme is funded through fees from the producers. For packaging and some products, a material-specific fee is charged per kg of mass. For other products, a specific fee will be charged per item. This basic set-up will be common all through the EU. However, individual Member States are allowed to organize the EPR scheme in a way that fits the national conditions. They can also vary the charge per item or kg depending on the design of the product to stimulate design for recycling and material efficiency.

\subsubsection{Technical Requirements}

This instrument entails the development of international standards and of technical requirements for specific metals products and metals components that are sold and used in the EU. These documents regulate the design of these products and components to, for example:

- Improve the modularity to increase reparability and reuse of components, taking into account impacts on energy efficiency;

- $\quad$ Reduce the unnecessary use of material; and

- Substitute metals with other materials when appropriate; for example, shifting from copper water-piping to polymer piping.

\subsubsection{Environmental Taxes}

The internalization of external environmental costs is part of a green fiscal reform in this policy mix. It is based on the Polluter Pays Principle, which was adopted by the Organization for Economic Cooperation and Development already in 1972 [65], and entails a gradual increase in taxes and fees on emissions and natural resources until all environmental costs are internalized.

The increased environmental taxes discussed here are not metal-specific but are also levied on other natural resources that are extracted in Europe (raw materials, energy, and water) and on emissions that occur in all economic sectors in Europe. This will help form a coherent package, increase material efficiency and, at the same time, avoid simply shifting of environmental burdens from the metals industry and metals products to other sectors or commodities:

- Raw materials: these include metal ores, but also the raw materials used to produce materials that clearly compete with metals (concrete, wood, etc.);

- Energy resources: a significant share of the energy resources are used to produce commodities for metals production (coal used to produce coke for crude-iron production, fuel used to produce 
electricity for primary aluminum production, etc. [66]). Oil and natural gas are used for producing polymers that compete with metals in certain applications. Energy resources used for other purposes are also relevant to include, because shifting from metals to other materials might affect the demand for energy resources in the manufacturing, use, and waste management of the products. Including all energy resources in the instrument safeguards against simply shifting from metals products to products and services with a higher energy demand in these parts of the product life cycles;

- Water: water use could be affected when shifting from steel products to wood or other materials based on biomass. A shift from metals products to other solutions might also affect the water used in the manufacturing and use phase of the products. These effects might not be significant, and the external costs associated with the use of water are probably the least clearly connected to metals. However, the external costs of water use are still included in the instrument, partly to form a coherent whole and to safeguard against unknown risks of burden shifting; and

- Emissions: metals production and metals processing are important point sources for emissions of, for example, $\mathrm{CO}_{2}$, and heavy metals. The production of competing materials, such as concrete and polymers, is also associated with significant emissions. Shifting from metals to other materials will affect the emissions from manufacturing, use, and/or waste management of the products. Including all emissions in the instrument safeguards against simply shifting from metals products to products and services with a higher environmental impact in the life cycle as a whole.

The environmental taxes will be specified per $\mathrm{kg}$ of pollutant or ton of material. It will be paid to the national government. The revenues will be used to fund other policy instruments in the policy mix and to reduce taxes on labor.

The implementation of the environmental taxes will be spearheaded by a coalition of willing Member States. It will be expanded until, eventually, all of EU has implemented the instrument.

\subsubsection{Border-Tax Adjustments}

As described in Section 3.3.1, the materials tax is levied on all materials that are used in the EU. In order not to shift materials production outside the EU, the tax will be levied on the material regardless of where it is produced, but not on exported materials. The tax is levied on imported, as well as on domestic materials in order not to distort the competitiveness of domestic material production in the EU. Exported materials are exempt from the tax in order not to distort the competitiveness of domestic material production outside the EU.

In order to reduce the risk that materials are exported to avoid the tax and then imported again as products, the tax also applies to simple imported products such as wires, pipes, etc., where the materials tax is a significant share of the total production cost (for details, see [42]). The tax exemption applies not only to exported materials but also to similarly simple products.

To reduce the impacts of environmental taxes on the competitiveness, border-tax adjustments can in principle be implemented also for the environmental taxes. This would ideally result in a full internalization of external costs of production outside the EU, when the products are imported to the EU. It would also mean an exemption from environmental taxes for products that are exported from the EU. In practice, border-tax adjustments with respect to external costs are difficult to implement, because it requires that the external costs are agreed upon. To reduce distortions to the competitiveness caused by environmental taxes, we propose that the EU strives in this direction.

\subsubsection{Labor Tax Reductions}

Part of the revenues from the materials tax and the environmental taxes will be used for funding the rest of the policy mix. As a very crude estimate, this might require half of the materials tax and half of the increase in environmental taxes until the year 2030 and then remain at the same level. The rest of the revenues will be used for reducing labor taxes. This means labor taxes can decline slowly 
until 2030 and more rapidly after that. Reductions in taxes on labor or investments is a vital part of a green fiscal reform ( $c f$. Section 1).

\subsubsection{Research and Development}

This instrument implies continued and strengthened public funding of research and development (R and D) in EU-27 for recycling and material efficiency. The R and D for recycling will include:

- Design for recycling;

- Efficient and consumer-adapted systems for collection, and identification of the role for the public sector in ensuring their provision;

- Technology for dismantling and separation of components and material; and

- Technology for recycling.

The $\mathrm{R}$ and $\mathrm{D}$ for material efficiency will include, for example:

- Improved processes and products;

- New business models; and

- Non-material alternatives for safe investments.

The objective of the last item in the list is to find ways to substitute metals, particularly gold, with other ways of delivering the service safe investments.

\subsubsection{Removal of Harmful Subsidies}

A complementary part of the green fiscal reform is the removal of two environmentally harmful subsidies: limited liability for accidents related to metals extraction, and subsidies associated with the purchase of company cars. These subsidies are selected here because they are both related to metals. They affect the mining of metal ores and the size and number of cars.

The money saved through the removal of these subsidies will be used for reducing the tax on labor, just like the material tax (Section 3.3.1) and the environmental taxes (Section 3.3.4). The monetary flows involved in the harmful subsidies are likely to be relatively small, compared to the taxes. A study for Belgium and Netherlands shows that company car taxation, i.e., favorable treatment of company cars in company accounting, cost the Belgian government around 4 billion EUR and the Dutch government 1.5 billion EUR in 2008 [67]. Macroeconomic and environmental impacts are likely to be correspondingly small. However, they are both likely to be positive. Removing environmentally harmful subsidies implies a benefit for the environment. At the same time, it removes distortions in the market, which makes the economy more efficient. The instrument can also be important to make the green fiscal reform easier to communicate and comprehend.

\subsubsection{Support to Sharing Systems}

Sharing systems for cars, bicycles, tools, and equipment are established by local authorities or through economic support to private initiatives. The sharing systems for bicycles, cars, and tools will mainly be set up in urban areas, including cities, towns, and larger villages. Sharing systems for agricultural equipment will be established in rural areas.

A combination of the following options will be implemented, depending on local and national conditions, etc.:

(1) Local authorities set up a scheme for sharing of cars, bicycles, tools, and equipment;

(2) Local authorities support the setting up of private sharing systems through funding of part of the investment cost; and 
(3) National authorities support the private sharing systems

a Through deductions in income tax to consumers for the renting costs, or

b Through a differentiation in VAT between goods and services.

This is part of a package to make leasing and sharing of products more convenient, compared to owning the same products.

\subsubsection{Advanced Recycling Centers}

This instrument aims to increase reuse and recycling and also to decrease the demand for (new) products through increased longevity. Its objective is to increase collection of waste for recycling and also to facilitate second-hand trade, repair, and redesign of used goods.

This instrument implies that local or national governments support community initiatives aimed at enhanced reuse, and invest in advanced recycling/reuse centers that include:

- Facilities for collection of recyclable fractions;

- Second-hand shops of building components, clothes, furniture, etc.;

- Repair shops for furniture, bicycles, tools, etc.; and

- Shops for redesign of waste products into art or new useful products.

Visitors to the recycling center are welcomed by personnel who help them to search the waste for items that can be reused, repaired, or redesigned rather than discarded [68]. In addition, businesses are encouraged to work with the recycling/reuse centers to identify products capable of reuse, reconditioning, and re-entering the market.

\subsubsection{Education Programs}

This supportive instrument aims to reduce the barriers related to unemployment and a mismatch between the workforce and the skills required as the policy mix shifts the structure of the economy from production of materials and goods to services and new business models. It includes the development and implementation of programs for retraining of workers in sectors where unemployment is likely to occur in order to give them the skills required in sectors that are likely to grow.

The EU also develops a strategy for mainstreaming resource efficiency aspects into relevant academic and vocational curricula (economics, engineering, marketing, architecture, design, business accounting, land management, craftsmen, etc.) and training for professionals to develop skills and techniques relevant for implementing resource efficiency measures in existing firms or developing new business models. The Strategic Energy Technology (SET) Plan Roadmap on Education and Training could provide a useful blueprint [69].

It is important to address both white collar and blue collar jobs. Therefore, the skill enhancement program will have to have targeted programs, contents, and design for (i) professionals and leaders responsible for strategic decisions, implementation of innovations, etc.; and (ii) broader programs which provide workers with "green" skills suitable for the new business models. Thus, both the necessary changes on managerial and leadership level can be initiated, as well as the swift reallocation of workers can be organized, which is a necessary part of the decoupling.

\subsubsection{Fora for Communication}

This instrument aims to facilitate communication throughout the value chain of priority products, to enable innovation, where current co-ordination structures do not yet exist (as they already do in the vehicle industry). The EU will co-fund the establishment of fora for nations and regions where appropriate, depending on the industrial structure of the value chain. It will co-ordinate an EU-level 
mechanism for value-chain co-operation and co-ordination. Such co-ordination can fulfil several purposes, for example:

- Giving producers and recyclers the opportunity to discuss what quality of the recycled materials can be obtained and what quality of the material is required for different applications. This can serve to establish or strengthen the markets for recycled material and increase recycling levels; and

- Creating critical mass between purchasers and suppliers in value chains, that allow sufficient purchasers and suppliers to innovate, in the knowledge that their innovation will have a market (suppliers) or will be able to benefit from innovative components (purchasers).

\subsubsection{Strategy for Dematerialization}

Developing an EU strategy for dematerialization is a supporting instrument. It aims to change the mindset of national policy-makers and to pave the way for the material tax and other ambitious policy instruments. The strategy is an official EU document and is primarily an industrial and economic strategy. The process for agreement of the strategy is essential for its political credibility, involving engagement of major industrial groups and Member State economics and finance ministries.

It makes explicit links to the impact of greater resource productivity on macroeconomic change, employment and well-being, in the context of expected low, future EU GDP growth. The development of the strategy should begin immediately, and inform economic performance assessment under the European Semester. The document should be ready and agreed upon by the Member States around the year 2020. It includes the plans for achievement of certain dematerialization objectives in the context of strategic structural change, in particular pointing to the price trends and other market changes which policy will look to deliver to bring about dematerialization. Its goal is to create credible market expectations of change, to give economic actors ample time to prepare for them and change their investment, innovation, and depreciation strategies. The document will, therefore, agree the nature of the instruments to be used to achieve change in market conditions.

\subsubsection{Information Campaigns}

This instrument aims to change the mindset of the public, authorities, and companies. One goal is to increase public acceptance of the other policy instruments. Another goal is to influence the consumption pattern and related behavior. This can be beneficial for all strategies for reducing the use of all virgin metals through product redesign, increased longevity, and increased recycling. The information campaigns can have broad or narrow topics and targets, for example:

- Counteracting commercials by pointing at alternative routes to well-being that do not involve increased consumption; and

- Encourage people to buy jewelry produced from materials with lower environmental impacts than gold.

\section{Discussion}

\subsection{Usefulness of the Sensitivity Model}

We applied the Sensitivity Model as a tool to map the relevant drivers. The procedure of the Sensitivity Model involves a consensus process to agree on the causal relationships between the selected variables. This consensus process offered an opportunity for mutual learning among the participants. We also found the results from the Sensitivity Model useful for illustrating the web of drivers involved in the use of metals. However, the procedure did not generate any new findings. We had already found all of the facts we used for identifying the drivers in the statistics, the literature, and our background knowledge. In our case, the Sensitivity Model did not serve to gain new knowledge, but to structure and present the knowledge we already had. 
The number of causal relationships in the Sensitivity Model grows with the square of the number of variables. With 29 variables, there are $29 \times 28=812$ possible relationships between different variables. Finding consensus on such a large number of causal relationships is a cumbersome process. Adding just one more variable would increase the number of relationships to 870 . For the procedure to be manageable, the number of variables needs to be severely restricted. This means that the Sensitivity Model can only cope with a very simplified model of the extremely complex system that would be affected by our policy mix.

\subsection{The Materials Policy Mix}

We used the heuristic framework of Givoni et al. [38] to develop the policy mix presented in this paper. A diverse but small author team was given the task to develop the policy objectives, identify drivers and barriers, and select promising policy instruments. We found that the policy mix could be significantly improved through input from stakeholder workshops and other findings of the DYNAMIX project. The EPR and the education programs are, for example, inspired by, although not identical to, instruments in the overarching policy mix [42]. Hence, interaction with other researchers, stakeholders, and/or policy-makers can, and should, play a role in at least Step 3 in the heuristic framework used.

The policy instruments outlined in the results section jointly serve the purpose to (i) raise the cost of using materials, relative to labor; (ii) increase the supply of recyclable materials; and, thus, (iii) reduce virgin material use and alleviate supply risks. In our policy mix concept, we aimed at combining primary (key) instruments with supportive instruments in a way that improves the conditions for the primary instruments to better take effect.

Findings from the qualitative ex-ante assessments indicate that the policy mix is beneficial from environmental and health perspectives, and also that it is largely consistent with existing EU legislation and WTO law $[45,47,48])$. However, from the assessments and the exchange in the policy mix team some pointers for revising the materials policy mix (Stage (5) in the heuristic framework used) emerged and were at least partly implemented.

\subsubsection{Pointers for Revising the Taxes}

The policy mix will probably not be sufficient to reach the target of $80 \%$ less use of virgin metals. This is despite the fact that the policy mix includes at least two strong primary instruments: a high materials tax, and environmental taxes that aim at fully internalizing environmental costs. The uncertainty is large in the quantitative ex-ante assessment of the policy mix, for example because the outcome of supportive instruments, such as $\mathrm{R}$ and $\mathrm{D}$ and fora for communication is not possible to quantitatively assess [44].

Unilateral European policies can be expected to have a negative impact on the competitiveness of European industries. This is perhaps particularly true for companies that are severely affected by the environmental taxes in the policy mix. The other strong instrument outlined here, the materials tax, has been designed to reduce the impacts on competitiveness through border-tax adjustments. There might also be an important temporal dimension in the impacts on competitiveness. While, in the short term, we may expect a reduction in competitiveness due to higher production costs, in the long term, this may result in an advantage due to the implicit and explicit efforts (at firm, industry, and economy levels) to boost green innovation and act as a main (or the first) player in a future economic system characterized by constraints to further exploitation of scarce resources.

European companies will also benefit from the reduction in labor taxes that are part of the green fiscal reform. This could serve to shift the structure of the economy from polluting industry and transports to services, and to other companies that, to a larger extent, depend on labor.

A transition to new economic structures has winners as well as losers. The policy mix is likely to, at least temporarily, increase unemployment in certain sectors, regions, and countries. It might also 
create a surplus of jobs in other sectors or locations, jobs that require a new set of skills. The education program is an important supportive instrument to make the transition smoother.

The ex-ante assessment indicates that the materials tax and the environmental tax are politically contentious, which means they can be difficult to implement [49]. When we presented the policy mix to stakeholders in the DYNAMIX policy platforms, the materials tax raised many questions and much discussion. Even if environmental taxes are accepted on a conceptual level, agreeing on the monetary value of environmental/health externalities and pricing the resource depletion risks are likely to be contentious issues.

The policy mix might be particularly difficult to accept because the two taxes partly overlap and can be considered a double taxation of the material-related environmental impacts. Full internalization might not be sufficient to reach an externally given target, such as the $80 \%$ reduction in virgin metals use, but it should in theory be sufficient to reduce resource consumption and pollution to levels that are optimal from a societal perspective.

However, in practice there are several barriers to the development towards such an optimum, as discussed in Section 3.2.2. For example, investments in environmental technology is not the core business of companies. This means that less attention and capital is available and a higher rate of return on the investment is required. As a result, investments in efficiency or pollution control are often not made even when they are profitable. Neither producers nor consumers have full knowledge of the total cost of ownership, which means that products tend to be optimized from the perspective of production cost rather than the life cycle cost. A double taxation might help overcome these barriers.

\subsubsection{Pointers for Revising the EU Strategy for Dematerialization}

Preparing and implementing the proposed EU strategy for dematerialization should build on the lessons learned from the processes around the overhaul of the EU Circular Economy Package, which consists of the EU Action Plan for the circular economy (COM (2015) 614 final) and proposed amendments of several EU Directives (on Waste, Packaging Waste, Landfill, end-of-life vehicles, batteries and accumulators and waste batteries and accumulators, and waste from electrical and electronic equipment). Initially launched in July 2014 by Environment Commissioner Potocnik under the Barroso II Commission, it was taken back in late December 2014 in the context of the new 2015 work program of the incoming Juncker Commission in order to be re-tabled in a more ambitious version in late 2015, which was finally released on 2 December 2015.

Independent of the many discussions regarding the level of ambition of the new package and harsh critiques from non-governmental organizations (NGOs; e.g., regarding lowered recycling targets for household waste and packaging waste and the removal of any resource efficiency target; see, for instance, [70]). This process indicates that preparing EU-wide strategies requires strong and long-term coalitions to hold beyond terms of political actors. Furthermore, the fact that the new package grants some Member States longer extension periods for complying with the targets highlights that a longer term focus is needed to envision a more ambitious EU policy on a circular economy.

In this light, it seems, at present, politically unlikely that an additional strategy on dematerialization will be able to be agreed upon by 2020 . In fact, the proposed EU strategy for dematerialization could be designed as a step-wise expansion of the circular economy package to increase coverage of, and linkages to, resource efficiency aspects and documents (such as the EU Roadmap to a Resource Efficient Europe, COM(2011) 571 final). This would have to include careful monitoring of opportunities when best to introduce such an expanded package of issues of dematerialization contributing to alleviating expected low, future EU GDP growth, as well as to improvements in well-being.

\subsubsection{Using Mitigating and Synergetic Instrument Combinations}

The chosen combination of instruments not only minimizes contradictions between instruments (i.e., being consistent), but it also enables synergetic effects and positive interactions (i.e., being coherent) 
due to the enabling framework effects of the supportive instruments. The instruments in the policy mix are designed to make the two taxes somewhat easier to accept. It includes border-tax adjustments to reduce the impact on the competitiveness of European industry. The environmental tax is based on the well-established Polluter Pays Principle. Both are part of a green fiscal reform that funds the rest of the policy mix and reduces labor taxes. Both are also raised gradually from the current levels to reach the ultimate level in the year 2050 (see Figure 5).

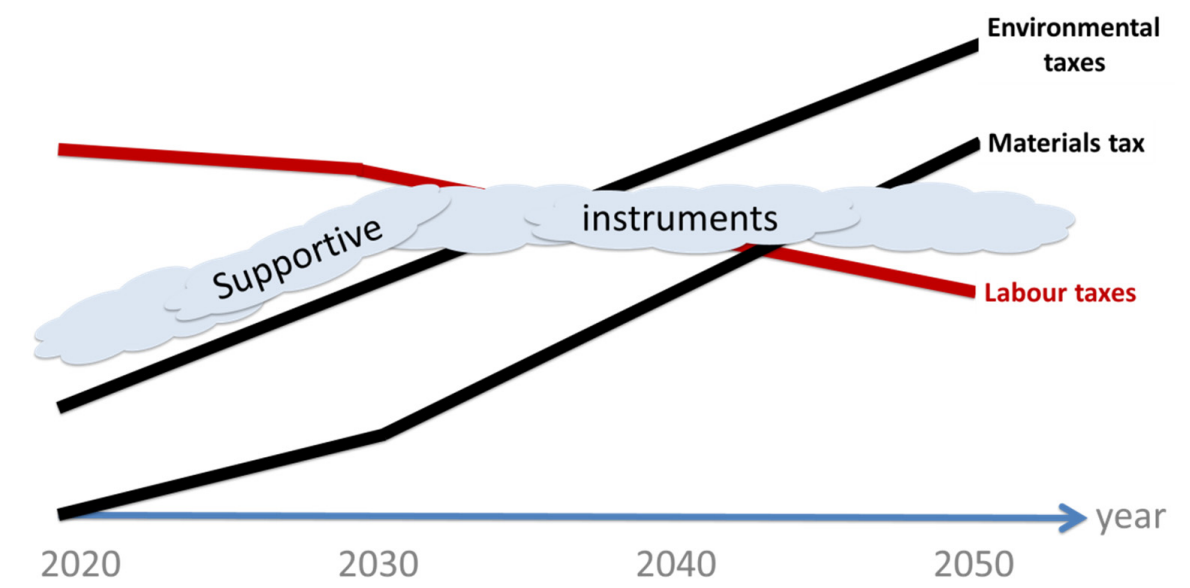

Figure 5. Qualitative illustration of the dynamics of the monetary flows in the green fiscal reform. Revenues from environmental and materials taxes increase gradually. They are first used mainly for establishing the rest of the supportive instruments. However, any surplus is used for reducing labor costs.

Even with these measures taken, the ex-ante assessments indicate that the policy mix will neither achieve an $80 \%$ reduction in virgin metals use by 2050 nor be easy to get accepted and implemented.

\subsection{Concept of Policy Mixing}

Applying and adapting the heuristic framework for policy mix design proved very interesting in the context of the DYNAMIX project. It allowed us to use different methods for identifying relevant drivers (literature review, the Sensitivity Model, and workshops) and helped guide both discussion on as well as the actual selection of potentially promising policy instruments aimed to achieve a wider set of environmental key targets. The discussion around which primary and supportive instruments to select because of which supposed interlinkages and synergetic effects was instrumental in shaping the understanding of the metals policy mix to be more than the sum of its instruments.

In light of the metals and materials policy mix, applying the concept and the conceptual design of policy mixing has proven useful because it:

- Required a deeper and as much as possible systemic understanding of a given problem situation, its system boundaries, and key drivers;

- Demanded clarifying objectives and concrete targets that policy shall achieve in relation to the problem situation;

- Asked for creating an overview (inventory) of policy instruments promising to help achieving the targets, but during the instrument selection urges to consider positive and negative interactions between the instruments to choose a consistent setup; and

- Necessitated to consider political processes that are supportive to or impeding the design and implementation of the policy mix.

Our findings point to the usefulness of comprehensive ex-ante assessments for designing promising and theoretically robust policy mixes. However, as the policy mix could be a combination of 
any instrument(s) that will support achieving the set policy objectives, the crucial design component is to select and combine those instruments which have the potential for maximizing synergetic effects and for mitigating negative side-effects of the use of other instruments (see [35]). While such design will benefit from scientific ex-ante assessments, it is complicated by two aspects:

(1) The inherent difficulty of assessing cumulative effectiveness of the mix vs. that of the individual instruments given potential synergetic and/or mitigating effects; and

(2) The logical gap between a scientific ex-ante assessment of a policy mix' potential effects on the one hand, and the actual implementation of the policy mix in the real-world of politics, multiple interests, and polycentric actor constellations, which will inevitably change the nature or design and, hence, the impacts of the mix through the political processes

Any policy mixing effort will have to undergo several adaptations along the life cycle of the policy mix, which may change it fundamentally from what is was based on an(y) initial scientific ex-ante assessment. The revision of the policy mix will have to continue during, and based on, the implementation (hence, requiring to draw further arrows from Stage (6) in the heuristic framework, Figure 1, to Stages (1)-(3)). This makes policy-making a cyclical, iterative and, thus, inherently long-term approach.

Still, both the policy mix concept and the heuristic framework applied offer promising routes to foster policy-making in resource policy (and environmental policy, in the wider sense). It puts a certain pressure on policy-making actors to go beyond so-called policy layering, where new instruments are stacked on top of existing instruments without consideration of potential instrument interactions and long-term strategies $[28,36]$.

The examples given in the introduction on the Icelandic fisheries and the UK aggregates policy mix may serve as a case in point for going beyond policy layering: in both cases the real-world policy mix has received additions over time where, based on initial environmental effects levelling off, either new instruments were introduced (individual tradable quotas, ITQs, in the early 1990s, and expanded to all commercial fishing vessels in 2004 in Iceland; [24]) or existing instruments revised (landfill and aggregates tax levels were raised at several times (e.g., 1997 and 1999 for the landfill tax; 2008 and 2009 for the aggregates levy) in the UK; [18]).

Furthermore, both policy mixes contributed positive or compensated negative side-effects through (a) making property rights much more efficient through the ITQs, which incentivized modernization and rationalization of the Icelandic fishing fleet, improved match-making between supply and demand and created marketable assets-all of which contributed to increasing Iceland's GDP growth rates between 1990 and 2006 [24,25]; and (b) in the case of the UK aggregates tax, economic impacts on affected industries were minimized by (i) exempting aggregates export from taxation and (ii) earmarking tax revenues to reduce employers' national insurance contributions by $0.1 \%$ and through the so-called Aggregates Levy Sustainability Fund (ALSF), which supports environmental management at aggregate sites and promotes greater use of recycled aggregates, thus transferring the revenues back to the affected industries [18].

Overall, the DYNAMIX approach for policy mixing advocates a more long-term ex ante assessment focus that could enable to maximize upfront policy mix consistency. Development of consistent and coherent policy mixes can contribute to a more effective strategy for policy-making. Nonetheless, neither the DYNAMIX approach nor any other ex ante assessment for that sake can navigate the political processes, which may impact both on the eventual policy mix design and on the implementation and, hence on the overall effectiveness of the mix. The concept of policy mixes appears to clash with current political realities and practical experience. Further research from organizational theory and political economy is required to investigate under what circumstances such strategic policy-making would be possible and through which actions its feasibility could be strengthened. Such research could possibly build on action research in practice settings. 
Designing politically feasible, and yet ambitious, policy mixes that have the potential to reconfigure systems remains a formidable challenge. This challenge relates both to their conceptualization and assessment of cumulative effects, as well as to reconciling long-term forward-looking policy strategies with political economies of election cycles and diverging interests in dynamic multi-actor settings. We suggest taking on this challenge with further scientific rigor, political creativity, and innovative coalitions because combining primary and supportive instruments into coherent and time-dynamic policy mixes appears a promising and enabling step on the way to fostering transition and reconfiguration of systems towards sustainability [71].

\section{Conclusions}

We used a heuristic, but systematic, framework for designing a policy mix for efficient use of material resources in the EU. We found the framework useful for this purpose, and also for presenting, discussing, and justifying the policy mix and its components. Interaction with stakeholders and external researchers is valuable in this systematic procedure. In the DYNAMIX project, such interaction gave important input to, and feedback on, the policy mix.

To reduce the risk of burden-shifting, a broad systems perspective is needed when designing a policy mix. This contributes to the complexity of the task, where a huge amount of information is potentially relevant to account for. We found the Sensitivity Model helpful for extracting, discussing, and presenting the most important information in the description of the current system (Section 3.2.1).

The distinction between primary and supportive policy instruments is useful when designing a policy mix, and also when presenting it (see Figures 4 and 5). The boundary between primary and supportive instruments is not sharp, however. Primary instruments aim to achieve the objectives of the policy mix, but are also designed to be as little controversial as possible. Supportive instruments aim to reduce barriers and negative side-effects of the primary instruments, but in several cases also contributes to achieving the policy objectives.

Our policy mix has the objectives to increase material efficiency, increase recycling, and substitute metals with more sustainable alternatives. We selected a primary instrument for each of these policy objectives: a materials tax, extended producer responsibility, and technical requirements, respectively. We also added environmental taxes with the aim to contribute to all three objectives. This resulted in a double taxation of, for example, the emissions and resource use from the production of material. Such over-taxation can perhaps be justified as a measure to overcome the barriers to investments in material-efficient technology and systems.

The policy mix includes a larger set of supportive instruments to reduce other barriers, as well as negative side-effects on competitiveness, economic growth, and employment. This contributed to fairly positive results from the environmental and economic models used for ex ante assessment of the policy mix [43,44]. However, the quantitative assessment results indicate that the policy mix will not be sufficient to reach the predefined target of reducing virgin metals use in the EU by $80 \%$ to the year 2050.

Acknowledgments: We are grateful to Adrian Tan, Christian Hudson and Doreen Fedrigo-Fazio who were among the original members of the author team that set out to develop the policy mix presented in this paper. Adrian Tan developed Figure 2 and Christian Hudson contributed to the description of the barriers. We are also grateful to the reviewers who contributed constructive suggestions, and to the European Commission for funding the research. The research leading to the presented findings has received funding from the European Union's Seventh Framework Programme for research, technological development and demonstration under grant agreement No. 308674, DYNAMIX project. Neither the European Commission nor any person acting on behalf of the Commission is responsible for the use which might be made of the following information. The views expressed in this publication are the sole responsibility of the authors and do not necessarily reflect the views of the European Commission. The funding source was not involved in study design; in the collection, analysis and interpretation of data; in the writing of the report; in the decision to submit the article for publication. However, it is EC policy to have FP7 project results published as much as possible within the scientific community, which the authors felt encouraged to do and hence decided to submit this article for publication. 
Author Contributions: Tomas Ekvall coordinated the development of the policy mix and wrote Sections 1, 2.2, 3, 4.1, 4.2 and 5. Martin Hirschnitz-Garbers wrote Sections 2.1 and 4.3 and contributed to the conceptualization of the method and paper. Fabio Eboli and Aleksander Sniegocki contributed to the development of the policy mix and provided feedback on manuscript drafts.

Conflicts of Interest: The authors declare no conflict of interest.

\section{Abbreviations}

The following abbreviations are used in this manuscript:

$\begin{array}{ll}\text { DYNAMIX } & \text { DYNAmic policy MIXes for absolute decoupling of environmental impacts of } \\ \text { EPR } & \text { EU resource use from economic growth (an EU FP7 research project) } \\ \text { EU } & \text { Extended producer responsibility } \\ \text { FP7 } & \text { European Union } \\ \text { GHG } & \text { 7th Framework Programme } \\ \text { Gt } & \text { Greenhouse gas } \\ \text { R and D } & \text { Gigatons } \\ \text { RMC } & \text { Research and development } \\ \text { VAT } & \text { Raw Material Consumption } \\ \text { WTO } & \text { Value-added tax } \\ \end{array}$

\section{References}

1. Krausmann, F.; Gingrich, S.; Eisenmenger, N.; Erb, K.H.; Haberl, H.; Fischer-Kowalski, M. Growth in global materials use, GDP and population during the 20th century. Ecol. Econ. 2009, 68, 2696-2705. [CrossRef]

2. Steffen, W.; Persson, A.; Deutsch, L.; Zalasiewicz, J.; Williams, M.; Richardson, K.; Crumley, C.; Crutzen, P.; Folke, C.; Gordon, L.; et al. The Anthropocene: From Global Change to Planetary Stewardship. Ambio 2011, 40, 739-761. [CrossRef] [PubMed]

3. Schaffartzik, A.; Mayer, A.; Gingrich, S.; Eisenmenger, N.; Loy, C.; Krausmann, F. The global metabolic transition: Regional patterns and trends of global material flows, 1950-2010. Glob. Environ. Chang. 2014, 26, 87-97. [CrossRef] [PubMed]

4. Wiedmann, T.O.; Schandl, H.; Lenzen, M.; Moran, D.; Suh, S.; West, J.; Kanemoto, K. The material footprint of nations. Proc. Natl. Acad. Sci. USA 2015, 112, 6271-6276. [CrossRef] [PubMed]

5. International Energy Agency (IEA). Energy Technology Perspectives 2008: Scenarios \& Strategies to 2050; IEA: Paris, France, 2008.

6. Brown, T.; Gambhir, A.; Florin, N.; Fennell, P. Reducing $\mathrm{CO}_{2}$ Emissions from Heavy Industry: A Review of Technologies and Considerations for Policy Makers; Briefing Paper No 7; Grantham Institute for Climate Change: London, UK, 2012.

7. Millennium Ecosystem Assessment. Ecosystems and Human Well-Being: Synthesis; Island Press: Washington, DC, USA, 2005.

8. Montzka, S.A.; Dlugokencky, E.J.; Butler, J.H. Non- $\mathrm{CO}_{2}$ greenhouse gases and climate change. Nature 2011, 476, 43-50. [CrossRef] [PubMed]

9. Galli, A.; Kitzes, J.; Niccolucci, V.; Wackernagel, M.; Wada, Y.; Marchettini, N. Assessing the global environmental consequences of economic growth through the Ecological Footprint: A focus on China and India. Ecol. Indic. 2012, 17, 99-107. [CrossRef]

10. Fischer-Kowalski, M.; Swilling, M.; von Weizsäcker, E.U.; Ren, Y.; Sadovy, Y.; Crane, W.; Krausmann, F.; Eisenmenger, N.; Giljum, S.; Hennicke, P.; et al. Decoupling Natural Resource Use and Environmental Impacts from Economic Growth; Report of the Working Group on Decoupling to the International Resource Panel; United Nations Environment Programme: Paris, France, 2011.

11. Steffen, W.; Richardson, K.; Rockström, J.; Cornell, S.E.; Fetzer, I.; Bennett, E.M.; Biggs, R.; Carpenter, S.R.; de Vries, W.; de Wit, C.A.; et al. Planetary Boundaries: Guiding human development on a changing planet. Science 2015, 347, 1259855:1-1259855:10. [CrossRef] [PubMed] 
12. Moore, D.; Galli, A.; Cranston, G.R.; Reed, A. Projecting future human demand on the Earth's regenerative capacity. Ecol. Indic. 2012, 16, 3-10. [CrossRef]

13. Van den Berg, M.; Bakkes, J.; Bouwman, L.; Jeuken, M.; Kram, T.; Neumann, K.; van Vuuren, D.P.; Wilting, H. EU Resource Efficiency Perspectives in a Global Context; PBL Netherlands Environmental Assessment Agency: The Hague, The Nederlands, 2011.

14. Allwood, J.M.; Ashby, M.F.; Gutowski, T.G.; Worrell, E. Material efficiency: A white paper. Resour. Conserv. Recycl. 2011, 55, 362-381. [CrossRef]

15. Ekvall, T., Malmheden, S., Eds.; Towards Sustainable Waste Management-Popular Summary Report from a Swedish EPA Research Programme; Report C69'; IVL Swedish Environmental Research Institute: Stockholm, Sweden, 2014; Available online: http://www.sustainablewaste.info/download/ 18.343dc99d14e8bb0f58b602/1439884437777/C69\%2BTOSUWAMA\%2Breport\%2B.pdf (accessed on 15 March 2016).

16. Binswanger, M. Technological progress and sustainable development: What about the rebound effect? Ecol. Econ. 2001, 36, 119-132. [CrossRef]

17. Lindhqvist, T. Extended Producer Responsibility in Cleaner Production-Policy Principle to Promote Environmental Improvements in Product Systems. Ph.D. Dissertation, 2000. Available online: http:/ /lup.lub.lu.se/luur/download?func=downloadFile\&recordOId=19692\&fileOId=1002025 (accessed on 15 March 2016).

18. Söderholm, P. Taxing virgin natural resources: Lessons from aggregates taxation in Europe. Resour. Conserv. Recycl. 2011, 55, 911-922. [CrossRef]

19. Nicolli, F.; Mazzanti, M. Landfill diversion in a decentralized setting: A dynamic assessment of landfill taxes. Resour. Conserv. Recycl. 2013, 81, 17-23. [CrossRef]

20. Sahlin, J.; Ekvall, T.; Bisaillon, M.; Sundberg, J. Introduction of a waste incineration tax: Effects on the Swedish waste flows. Resour. Conserv. Recycl. 2007, 51, 827-846. [CrossRef]

21. Söderholm, P.; Tilton, J.E. Material efficiency: An economic perspective. Resour. Conserv. Recycl. 2012, 61, 75-82. [CrossRef]

22. Finnveden, G.; Ekvall, T.; Arushanyan, Y.; Bisaillon, M.; Henriksson, G.; Gunnarsson Östling, U.; Ljunggren Söderman, M.; Sahlin, J.; Stenmarck, Å.; Sundberg, J.; et al. Policy instruments towards a sustainable waste management. Sustainability 2013, 5, 841-881. [CrossRef]

23. OECD. Instrument Mixes for Environmental Policy; OECD Publishing: Paris, France, 2007.

24. Arnason, R. Iceland's ITQ system creates new wealth. Electron. J. Sustain. Dev. 2008, 1, 35-41.

25. Haraldsson, G.; Carey, D. Ensuring a Sustainable and Efficient Fishery in Iceland; OECD Economic Department Working Paper No. 89; OECD: Paris, France, 2011; Available online: http:/ /www.oecd.org/ officialdocuments/publicdisplaydocumentpdf/?cote=ECO/WKP\%282011\%2960 (accessed on 23 March 2016).

26. Ecorys. The Role of Market-Based Instruments in Achieving a Resource Efficient Economy. Available online: http:/ / blogs.ec.europa.eu/orep/the-role-of-market-based-instruments-in-achieving-a-resource-efficienteconomy/ (accessed on 23 March 2016).

27. Lindhjem, H.; Magne Skjelvik, J.; Eriksson, A.; Fitch, T. The Use of Economic Instruments in Nordic Environmental Policy 2006-2009; Nordic Council of Ministers: Copenhagen, Denmark, 2009.

28. Howlett, M.; Rayner, J. Design Principles for Policy Mixes: Cohesion and Coherence in "New Governance Arrangements". Policy Soc. 2007, 26, 1-18. [CrossRef]

29. Pearce, D. The Role of Carbon Taxes in Adjusting to Global Warming. Econ. J. 1991, 101, 938-948. [CrossRef]

30. Zárate-Marco, A.; Vallés-Giménez, A. Environmental tax and productivity in a decentralized context: New findings on the Porter hypothesis. Eur. J. Law Econ. 2015, 40, 313-339. [CrossRef]

31. De Miguel, C.; Manzano, B. Gradual green tax reforms. Energy Econ. 2011, 33 (Suppl. 1), S50-S58. [CrossRef]

32. Gunningham, N.; Young, M.D. Toward Optimal Environmental Policy: The Case of Biodiversity Conservation. Ecol. Law Q. 1997, 24, 243-298.

33. Gunningham, N.; Grabosky, P.; Sinclair, D. Smart Regulation: Designing Environmental Policy; Clarendon Press: Oxford, UK, 1998.

34. Howlett, M. Beyond Good and Evil in Policy Implementation: Instrument Mixes, Implementation Styles and Second Generation Theories of Policy Instrument Choice. Policy Soc. 2004, 23, 1-17. [CrossRef]

35. Minogue, M. Governance-Based Analysis of Regulation. Ann. Public Coop. Econ. 2002, 73, 649-666. [CrossRef] 
36. Del Rio, P.; Howlett, M. Beyond the "Tinbergen Rule" in Policy Design: Matching Tools and Goals in Policy Portfolios. Annu. Rev. Policy Des. 2013, 1, 1-6. [CrossRef]

37. DYNAMIX. Decoupling growth from resource use and its environmental impacts. Available online: www.dynamix-project.eu (accessed on 12 April 2016).

38. Givoni, M.; Macmillen, J.; Banister, D.; Feitelson, E. From Policy Measures to Policy Packages. Trans. Rev. 2013, 33, 1-20. [CrossRef]

39. Rogge, K.S.; Reichardt, K. Towards a More Comprehensive Policy Mix Conceptualization for Environmental Technological Change: A Literature Synthesis; Working Paper “Sustainability and Innovation" No. S 3/2013; Fraunhofer ISI: Karlsruhe, Germany, 2013.

40. Umpfenbach, K. How Will We Know If Absolute Decoupling Has Been Achieved and Will It be Enough?-Common Approach for DYNAMIX; DYNAMIX Project Deliverable D 1.3; Ecologic Institute: Berlin, Germany, 2013; Available online: http://dynamix-project.eu/how-will-we-know-if-absolutedecoupling-has-been-achieved-and-will-it-be-enough-common-approach (accessed on 14 March 2016).

41. Vester, F. The Art of Interconnected Thinking. In Tools and Concepts for a New Approach to Tackling Complexity, 1st ed.; MCB Publishing House: Munich, Germany, 2007.

42. Ekvall, T.; Elander, M.; Umpfenbach, K.; Hirschnitz-Garbers, M.; Hudson, C.; Wunder, S.; Nesbit, M.; Keenleyside, C.; Mazza, L.; Russi, D.; et al. Development of DYNAMIX Policy Mixes; DYNAMIX Project Deliverable D 4.2; IVL Swedish Environmental Research Institute: Stockholm, Sweden; Gothenburg, Sweden, 2015; Available online: http:/ / dynamix-project.eu/development-dynamix-policy-mixes (accessed on 14 March 2016).

43. Ekvall, T.; Martin, M.; Palm, D.; Danielsson, L.; Fråne, A.; Laurenti, R.; Oliveira, F. Physical and Environmental Assessment; DYNAMIX Deliverable D6.1; IVL: Gothenburg, Sweden, 2016; Available online: http:/ / dynamix-project.eu/results (accessed on 15 March 2016).

44. Bosello, F.; Antosiewicz, M.; Bukowski, M.; Eboli, F.; Gąska, J.; Śniegocki, A.; Witajewski-Baltvilks, J.; Zotti, J. Report on Economic Quantitative Ex-Ante Assessment of DYNAMIX Policy Mixes; DYNAMIX Deliverable D6.2; FEEM: Milano, Italy, 2016; Available online: http:/ /dynamix-project.eu/results (accessed on 15 March 2016).

45. Nesbit, M.; Watkins, E.; Harris, S. Environmental Assessment of DYNAMIX Policy Mixes; DYNAMIX Project Deliverable D5.1; Institute for European Environmental Policy: London, UK, 2015; Available online: http://dynamix-project.eu/assessment-environmental-impacts-dynamix-policy-mixes (accessed on 14 March 2016).

46. Bigano, A.; Zotti, J.; Bukowski, M.; Śniegocki, A. Qualitative Assessment of Economic Impacts; DYNAMIX Project Deliverable D 5.2; FEEM: Milan, Italy; Venice, Italy, 2015; Available online: http:/ / dynamix-project.eu/economic-assessment-dynamix-policy-mixes (accessed on 14 March 2016).

47. Bukowski, M.; Śniegocki, A.; Gąska, J.; Trzeciakowski, R.; Pongiglione, F. Report on Qualitative Assessment of Social Impacts; DYNAMIX Project Deliverable D 5.3; WISE Institute: Warsaw, Poland, 2015; Available online: http:/ / dynamix-project.eu/social-assessment-dynamix-policy-mixes (accessed on 14 March 2016).

48. Lucha, C.; Roberts, E. Legal Assessment of DYNAMIX Policy Mixes; DYNAMIX Project Deliverable D 5.4.1; Ecologic Institute: Berlin, Germany, 2015; Available online: http://dynamix-project.eu/ legal-assessment-dynamix-policy-mixes (accessed on 14 March 2016).

49. Vanner, R.; Bicket, M.; Elliott, B.; Harvey, C. Public Acceptability of DYNAMIX Policy Mixes; DYNAMIX Project Deliverable D 5.4.2; PSI: London, UK, 2015; Available online: http://dynamix-project.eu/ assessment-public-acceptability-dynamix-policy-mixes (accessed on 14 March 2016).

50. Bringezu, S. Visions of a sustainable resource use. In Sustainable Resource Management: Global Trends, Visions and Policies; Bringezu, S., Bleischwitz, R., Eds.; Greenleaf Publishing: Sheffield, UK, 2009; pp. 155-215.

51. Mara, V.; Haghani, R.; Sagemo, A.; Storck, L.; Nilsson, D. Comparative study of different bridge concepts based on life-cycle cost analyses and life-cycle assessment. In Proceedings of the 2013 Asia-Pacific Conference on FRP in Structures (APFIS 2013), Melbourne, Australia, 11-13 December 2013; Al-Mahaidi, R., Smith, S.T., Bai, Y., Zhao, X.L., Eds.; International Institute for FRP in Construction (IIFC): Melbourne, Australia. Available online: http://publications.lib.chalmers.se/records/fulltext/193796/local_193796.pdf (accessed on 21 March 2016).

52. Guggemos, A.; Horvath, A. Decision support tool for environmental analysis of commercial building structures. In Proceedings of the Construction Research Congress, San Diego, CA, USA, 5-7 April 2005; pp. 1-11. 
53. Hirschnitz-Garbers, M.; Tan, A.; Gradmann, A.; Srebotnjak, T. Key drivers for unsustainable resource use-Categories, effects and policy pointers. J. Clean. Prod. 2015. [CrossRef]

54. Eurostat. Raw Material Equivalents. Available online: http://epp.eurostat.ec.europa.eu/portal/page/Portal/ environmental_accounts/documents/RME_project_Introduction.pdf (accessed on December 2013).

55. Allwood, J.; Cullen, J.M. Sustainable Materials—With Both Eyes Open; UIT Cambridge LTD: Cambridge, UK, 2011.

56. Eurofer (The European Steel Association). Sector Shares in Total EU Steel Consumption in 2010. Available online: http:/ /www.eurofer.org/About\%20Steel/Growing\%20with\%20Steel.fhtml (accessed on 14 March 2016).

57. Allwood, J.M.; Ashby, M.F.; Gutowski, T.G.; Worrell, E. Material efficiency: Providing material services with less material production. Philos. Trans. R. Soc. A 2013, 371, 20120496:1-20120496:15. [CrossRef] [PubMed]

58. European Copper Institute. Available online: http://www.copperalliance.eu/ (accessed on 13 January 2016).

59. World Gold Council. Gold Demand Trends; First Quarter 2014; World Gold Council: London, UK, 2014.

60. ECSIP Consortium. Treating Waste as a Resource for the EU Industry: Analysis of Various Waste Streams and the Competitiveness of Their Client Industries; ECSIP Consortium: Rotterdam, The Netherlands, 2013.

61. Graedel, T.E.; Allwood, J.; Birat, J.-P.; Reck, B.K.; Sibley, S.F.; Sonnemann, G.; Buchert, M.; Hagelüken, C. Recycling Rates of Metals-A Status Report; A Report of the Working Group on the Global Metal Flows to the International Resource Panel; United Nations Environment Programme: Paris, France, 2011.

62. Blomberg, J.; Söderholm, P. The economics of secondary aluminium supply: An econometric analysis based on European Data. Resour. Conserv. Recycl. 2009, 53, 455-463. [CrossRef]

63. Wyss, F. Modeling the Environmental Impacts of an Increased Market Demand for Products Manufactured from Recycled Materials. Master's Thesis, ETH Zürich, Zürich, Switzerland, August 2009.

64. Thollander, P.; Ottosson, M. An energy efficient Swedish pulp and paper industry-Exploring barriers to and driving forces for cost-effective energy efficiency investments. Energy Effic. 2008, 1, 21-34. [CrossRef]

65. Khan, M.R. Polluter-pays principle: The cardinal instrument for addressing climate Change. Laws 2015, 4, 638-653. [CrossRef]

66. IEA (International Energy Agency). Sankey Diagram: World-Final Consumption. 2013. Available online: http://www.iea.org/Sankey/index.html\#?c=World\&s=Final.consumption (accessed on 14 March 2016).

67. Copenhagen Economics. Company Car Taxation; Taxation Papers; Working Paper No. 22; European Commission, DG Taxation and Customs Union: Brussel, Belgium, 2010.

68. Ljunggren Söderman, M.; Palm, D.; Rydberg, T. Reducing Waste through Recycling Parks: Analysis of the Environmental Impact; Report B1958; IVL Swedish Environmental Research Institute: Gothenburg, Sweden, 2011.

69. JRC-IET. Strategic Energy Technology (SET) Plan Roadmap on Education and Training; Availability and Mobilisation of Appropriately Skilled Human Resources; Science and Policy Report by the Joint Research Centre of the European Commission; Publications Office of the European Union: Luxembourg, Luxembourg, 2014.

70. EEB (European Environmental Bureau). Smoke and Mirrors as Commission Issues Circular Economy Package with Weaker Waste Targets. Available online: http://www.eeb.org/index.cfm/news-events/ news/smoke-and-mirrors-as-commission-issues-circular-economy-package-with-weaker-waste-targets / (accessed on 14 March 2016).

71. Geels, F.W.; McMeekin, A.; Mylan, J.; Southerton, D. A critical appraisal of Sustainable Consumption and Production research: The reformist, revolutionary and reconfiguration positions. Glob. Environ. Chang. 2015, 34, 1-12. [CrossRef]

(C) 2016 by the authors; licensee MDPI, Basel, Switzerland. This article is an open access article distributed under the terms and conditions of the Creative Commons Attribution (CC-BY) license (http:/ / creativecommons.org/licenses/by/4.0/). 